Brigitte C. Widemann, MD

Jaishri O. Blakeley, MD

Eva Dombi, MD

Michael J. Fisher, MD

Clemens O. Hanemann, $\mathrm{MD}, \mathrm{PhD}$

Karin S. Walsh, PsyD

Pamela L. Wolters, PhD

Scott R. Plotkin, MD,

$\mathrm{PhD}$

Correspondence to

Dr. Widemann:

widemanb@mail.nih.gov

Supplemental data at www.neurology.org

\title{
Conclusions and future directions for the REiNS International Collaboration
}

\section{ABSTRACT}

The Response Evaluation in Neurofibromatosis and Schwannomatosis (REiNS) International Collaboration was established with the goal to develop consensus recommendations for the use of endpoints in neurofibromatosis (NF) clinical trials. This supplement includes the first series of REiNS recommendations for the use of patient-reported, functional, and visual outcomes, and for the evaluation of imaging response in NF clinical trials. Recommendations for neurocognitive outcome measures, the use of whole-body MRI in NF, the evaluation of potential biomarkers of disease, and the comprehensive evaluation of functional and patient-reported outcomes in NF are in development. The REiNS recommendations are made based on current knowledge. Experience with the use of the recommended endpoints in clinical trials, development of new tools and technologies, new knowledge of the natural history of NF, and advances in the methods used to analyze endpoints will likely lead to modifications of the currently proposed guidelines, which will be shared with the NF research community through the REiNS Web site www. reinscollaboration.org. Due to the clinical complexity of NF, there is a need to seek expertise from multiple medical disciplines, regulatory agencies, and industry to develop trial endpoints and designs, which will lead to the identification and approval of effective treatments for NF tumor and nontumor manifestations. The REiNS Collaboration welcomes anyone interested in providing his or her expertise toward this effort. Neurology ${ }^{\circledR}$ 2013;81 (Suppl 1):S41-S44

\section{GLOSSARY}

$\mathbf{N F}=$ neurofibromatosis; PN = plexiform neurofibroma; PRO = patient-reported outcome; $\mathbf{Q O L}=$ quality of life; $\mathbf{R E i N S}=$ Response Evaluation in Neurofibromatosis and Schwannomatosis; VS = vestibular schwannoma; WBMRI = whole-body MRI.

Neurofibromatosis 1 (NF1), neurofibromatosis 2 (NF2), and schwannomatosis share the predisposition to the development of multiple mostly benign nerve sheath tumors. However, there are distinct differences in the clinical manifestations between NF1, NF2, and schwannomatosis, and there is substantial variability in the development of disease manifestations within each of the forms of NF. ${ }^{1,2}$ As increasing numbers of clinical trials for NF-related tumor and nontumor manifestations are ongoing, the need for the development of standardized trial endpoints specifically for NF has emerged (see the introduction to this supplement, Plotkin et al.). The aim of the Response Evaluation in Neurofibromatosis and Schwannomatosis (REiNS) International Collaboration is to develop standardized endpoints for clinical trials for NF to allow for meaningful comparisons of trial results and to accelerate the development of active and beneficial agents.

This supplement provides the first series of recommendations of the REiNS collaborative group for endpoints in NF trials. The guidelines proposed in this supplement-for the evaluation of pain (Wolters et al.), hearing and facial function (Plotkin et al.), vision (Fisher et al.), and imaging of response (Dombi et al.) — can be readily incorporated as endpoints into clinical trials.

RECOMMENDATIONS UNDER DEVELOPMENT FROM REINS WORKING GROUPS The Neurocognitive, Whole-body MRI, and Biomarker Working Groups are currently preparing recommendations. Learning

From the Pediatric Oncology Branch (B.C.W., E.D., P.L.W.), National Cancer Institute, Bethesda, MD; Department of Neurology, Neurosurgery, and Oncology (J.O.B.), Johns Hopkins, Baltimore, MD; Division of Oncology, Department of Pediatrics (M.J.F.), The Children's Hospital of Pennsylvania, Philadelphia; Plymouth University Peninsula Schools of Medicine and Dentistry (C.O.H.), Plymouth, United Kingdom; The Jennifer and Daniel Gilbert Neurofibromatosis Institute (K.S.W.), Children's National Medical Center, Washington, DC; and Neurology Department and Cancer Center (S.R.P.). Massachusetts General Hospital, Boston, MA.

REiNS International Collaboration members are listed on the Neurology ${ }^{\circledR}$ Web site at www.neurology.org.

Go to Neurology.org for full disclosures. Funding information and disclosures deemed relevant by the authors, if any, are provided at the end of the article. 
disabilities and cognitive impairments are common in patients with NF1 and result in substantial disability. ${ }^{3}$ Clinical trials of statins for learning disability have been published and others are under way. ${ }^{4}$ In addition, trials of nonpharmacologic treatments for learning disability (e.g., Cogmed) are in the planning stages. The goal of the Neurocognitive group is to standardize endpoints for these trials to promote comparisons of efficacy between pharmacologic and nonpharmacologic intervention trials.

Tumor involvement in NF can be extensive and in some patients can affect virtually the entire body. Whole-body MRI (WBMRI) is an emerging technique to evaluate the entire tumor burden in the body in a short time (about 45 minutes), and it has been evaluated in patients with NF. ${ }^{5-8}$ The Whole-body MRI Working Group is tasked with evaluating the reproducibility and potential utility of WBMRI in clinical trials. Finally, the goals of the Biomarker Working Group include the identification of biomarkers of NF manifestations, including markers of disease progression, or of transformation of histologically benign plexiform neurofibromas $(\mathrm{PN})$ to malignant peripheral nerve sheath tumors.

The development of recommendations by REiNS is an ongoing and dynamic process. Below we highlight some challenges for ongoing and future work.

OPTIMAL USE OF FUNCTIONAL ENDPOINTS Change of tumor size is an important endpoint in clinical trials for benign NF tumors. Drugs that decrease tumor size are considered to be active and worthy of further study. However, to identify the benefits of new treatments and to achieve drug approval, it will be necessary to incorporate functional and patient-reported outcomes (PRO) into clinical trials. The functional measures proposed in this supplement for hearing in NF2 vestibular schwannomas and for acuity in NF1related optic pathway gliomas provide examples of how a meaningful functional outcome measure can be used as the primary trial endpoint. In these trials, change in tumor size should be included as a secondary endpoint. For other NF-related tumors, such as PN or extracranial schwannomas, a variety of morbidities may result from tumor growth depending on the location, size, and growth rate of the tumor. For example, tumors compressing the spinal cord or involving the brachial or lumbosacral plexus may result in weakness, whereas tumors affecting the airway or bowel and bladder may result in organ compromise. The Functional Endpoints Working Group is developing recommendations for reproducible functional outcome measures for each of the potential morbidities.

INCORPORATING PRO INTO TRIAL DESIGN Pain is the most common symptom in schwannomatosis ${ }^{2}$ and is present in approximately $50 \%$ of patients enrolled in clinical trials for NF1 and $\mathrm{PN}^{9,10}$ Therefore, the initial focus of the PRO Working Group was to provide recommendations for the evaluation of pain intensity (Wolters et al., this supplement). Recommendations are in preparation for pain interference, functional disability, and disease-specific and general quality of life (QOL). This task is challenging given the wide age range of affected individuals (from infants to older adults) and the extensive morbidities arising from tumor and nontumor manifestations in NF. The systematic method developed by the PRO group for reviewing, rating, and recommending measures described in this supplement will streamline this process and be applicable to the efforts of other working groups. As an example, the Visual Outcomes Working Group used this method to recommend a visual QOL scale as a secondary endpoint measure for optic pathway glioma trials. As much as possible, existing PRO measures will be recommended for use in NF clinical trials, although they need to be validated in the NF population. As reliable functional and $\mathrm{PRO}$ measures for NF become available, the goal will be to evaluate tumor size, function, and PROs simultaneously in trials, and to design trials with functional and PROs as primary endpoints.

DEVELOPMENT OF IMPROVED IMAGING OUTCOMES In this supplement, the Tumor Measurement Working Group proposes volumetric tumor measurements as opposed to standard 1- or 2-dimensional measurements for NF1-related PN and NF2-related vestibular schwannomas (VS). Furthermore, the group defines tumor progression and tumor response based on much smaller changes than solid tumor response criteria. ${ }^{8-10}$ These response criteria were chosen to maximize the identification of active agents and to minimize the duration of patients' exposure to inactive agents. However, there is a need for additional studies to validate and compare methods of volumetric analysis and to identify the percent changes that can be reliably measured for specific tumor types. Plans are under way to compare currently used methods of volumetric analysis of PN and VS to evaluate whether these can be used interchangeably in clinical trials. We will apply currently established response criteria for pediatric and adult CNS tumorsResponse Assessment in Neuro-Oncology (RANO) ${ }^{11,12}$ and Response Assessment in Pediatric Neuro-Oncology $(\mathrm{RAPNO})^{13}$ — to NF-related CNS tumors such as gliomas and meningiomas, if feasible.

In solid tumors, CT is frequently used to measure change in tumor size. This method may have advantages for NF patients with metal implants, which limit the utility of MRI for volumetric analysis. Studies evaluating the utility of CT for response evaluation in NF are thus another goal of the Tumor Measurement Working Group. 
The measurement of small decreases in tumor size allows for identification of active agents. Ultimately, studies that analyze the relationship between tumor size and changes in functional and patient-reported outcomes will be required to assess whether imaging changes can serve as a surrogate for morbidity. For example, while the degree of hearing loss in NF2 does not correlate directly with the size of VS, there may be a correlation between tumor size and morbidity for other tumors. Finally, consideration should be given to evaluating the utility of functional imaging, such as PET or magnetic resonance spectroscopy, in the assessment of response to targeted therapies in future research studies.

Our ultimate goal is to accelerate the identification of active and clinically beneficial agents for NF. The recent US Food and Drug Administration approval of the mammalian target of rapamycin (mTOR) inhibitor everolimus for patients with tuberous sclerosis complex and subependymal giant cell astrocytomas $(\mathrm{SEGA})^{14}$ and the Janus kinase inhibitor (JAK1/2) ruxolitinib for intermediate and high-risk myelofibrosis $^{15}$ serve as potential examples for future NF trials. These drugs were approved based on nonstandard outcomes. Everolimus was approved based on a reduction in tumor volume in patients enrolled in a single-arm trial. Ruxolitinib was approved based on 2 placebocontrolled trials using reduction in spleen volume as a primary endpoint and reduction in patient-reported symptoms as a key secondary endpoint.

Overall, the number of patients with NF available for participation in clinical trials is small. It is thus important that the most appropriate trial designs and endpoints are utilized. Early interaction and collaboration with regulatory agencies and industry will be critical to this process as trials with new endpoints and designs are developed.

\section{AUTHOR CONTRIBUTIONS}

BC Widemann: drafting the manuscript, study concept, interpretation of data. JO Blakeley: revising the manuscript for content, study concept, interpretation of data. E Dombi: revising the manuscript for content, study concept, interpretation of data. MJ Fisher: revising the manuscript for content, study concept, interpretation of data. CO Hanemann: revising the manuscript for content, study concept, interpretation of data. KS Walsh: revising the manuscript for content, study concept, interpretation of data. PL Wolters: revising the manuscript for content, study concept, interpretation of data. SR Plotkin: drafting the manuscript, study concept, interpretation of data.

\section{ACKNOWLEDGMENT}

The authors would like to acknowledge the support of the Children's Tumor Foundation for the REiNS International Collaboration and for this supplement.

\section{STUDY FUNDING}

Supported by the Children's Tumor Foundation and the intramura research program of the Center for Cancer Research, NCI.

\section{DISCLOSURE}

B. Widemann is a member of the scientific advisory board of the Neurofibromatosis Therapeutic Acceleration Program. She is a member of the editorial board of The Oncologist and an associate editor of Frontiers in Pediatric Oncology. J. Blakely received travel support from the Children's Tumor Foundation, the American Academy of Neurology, and the American Society of Clinical Oncology. She receives research support from GlaxoSmithKline, Sanofi-Aventis, Eli Lilly, the Cancer Therapy Evaluation Program, and the Children's Tumor Foundation. E. Dombi reports no disclosures. M. Fisher received reimbursement from the Children's Tumor Foundation to attend their annual Neurofibromatosis Conference, is funded by the Department of Defense (W81XWH-121-0155, W81XWH-05-1-0615), Thrasher Research Fund, the Children's Tumor Foundation, and Sarcoma Alliance for Research through Collaboration, and received research support from the Pediatric Low Grade Astrocytoma Foundation, Bayer, Children's Discovery Institute, NIH (NR009651-01), and the Department of Defense (W81XWH-08-10051). C. Hanemann received a travel grant from Baxter International and receives grant support from Novartis, The Brain Tumor Charity, CR-UK, and Action Medical Research. K. Walsh reports no disclosures. P. Wolters received research support from the Childhood Brain Tumor Foundation and holds stock options in Bristol-Meyers-Squibb, General Electric, and Zimmer Holdings, Inc. S. Plotkin has been reimbursed by the American Academy of Neurology and the Children's Tumor Foundation for travel for educational activities. He has received research support from the Department of Defense (W81XWH-091-0182, NF050202, W81XWH-12-1-0155, PI), the Children's Tumor Foundation (PI), and Johns Hopkins Medical Institutes (site PI). Go to Neurology.org for full disclosures.

Received May 10, 2013. Accepted in final form September 5, 2013.

\section{REFERENCES}

1. Ferner RE. Neurofibromatosis 1 and neurofibromatosis 2 : a twenty first century perspective. Lancet Neurol 2007;6: 340-351.

2. Merker VL, Esparza S, Smith MJ, Stemmer-Rachamimov A, Plotkin SR. Clinical features of schwannomatosis: a retrospective analysis of 87 patients. Oncologist 2012;17:1317-1322.

3. Acosta MT, Bearden CE, Castellanos FX, et al. The Learning Disabilities Network (LeaDNet): using neurofibromatosis type 1 (NF1) as a paradigm for translational research. Am J Med Genet A 2012;158A:2225-2232.

4. Acosta MT, Kardel PG, Walsh KS, Rosenbaum KN, Gioia GA, Packer RJ. Lovastatin as treatment for neurocognitive deficits in neurofibromatosis type 1 : phase I study. Pediatr Neurol 2011;45:241-245.

5. Cai W, Kassarjian A, Bredella MA, et al. Tumor burden in patients with neurofibromatosis types 1 and 2 and schwannomatosis: determination on whole-body MR images. Radiology 2009;250:665-673.

6. Jaremko JL, MacMahon PJ, Torriani M, et al. Wholebody MRI in neurofibromatosis: incidental findings and prevalence of scoliosis. Skeletal Radiol 2012;41:917-923.

7. Nguyen R, Dombi E, Widemann BC, et al. Growth dynamics of plexiform neurofibromas: a retrospective cohort study of 201 patients with neurofibromatosis 1 . Orphanet J Rare Dis 2012;7:75.

8. Plotkin SR, Bredella MA, Cai W, et al. Quantitative assessment of whole-body tumor burden in adult patients with neurofibromatosis. PLoS One 2012;7:e35711.

9. Kim A, Gillespie A, Dombi E, et al. Characteristics of children enrolled in treatment trials for NF1-related plexiform neurofibromas. Neurology 2009;73:1273-1279.

10. Nguyen R, Kluwe L, Fuensterer C, Kentsch M, Friedrich RE, Mautner VF. Plexiform neurofibromas 
in children with neurofibromatosis type 1: frequency and associated clinical deficits. J Pediatr 2011;159: 652-655 e2.

11. van den Bent MJ, Wefel JS, Schiff D, et al. Response assessment in neuro-oncology (a report of the RANO group): assessment of outcome in trials of diffuse lowgrade gliomas. Lancet Oncol 2011;12:583-593.

12. Wen PY, Macdonald DR, Reardon DA, et al. Updated response assessment criteria for high-grade gliomas: response assessment in neuro-oncology working group. J Clin Oncol 2010;28:1963-1972.
13. Warren KE, Poussaint TY, Vezina G, et al. Challenges with defining response to antitumor agents in pediatric neuro-oncology: a report from the response assessment in pediatric neuro-oncology (RAPNO) working group. Pediatr Blood Cancer 2013;60:1397-1401.

14. Franz DN. Everolimus: an mTOR inhibitor for the treatment of tuberous sclerosis. Expert Rev Anticancer Ther 2011;11:1181-1192.

15. Vaddi K, Sarlis NJ, Gupta V. Ruxolitinib, an oral JAK1 and JAK2 inhibitor, in myelofibrosis. Expert Opin Pharmacother 2012;13:2397-2407. 


\section{Neurology}

\section{Conclusions and future directions for the REiNS International Collaboration Brigitte C. Widemann, Jaishri O. Blakeley, Eva Dombi, et al. Neurology 2013;81;S41-S44 \\ DOI 10.1212/01.wnl.0000435748.79908.c5}

\section{This information is current as of November 18, 2013}

\section{Updated Information \& Services \\ Supplementary Material}

\section{References}

Citations

Subspecialty Collections

Permissions \& Licensing

\section{Reprints}

including high resolution figures, can be found at: http://n.neurology.org/content/81/21_supplement_1/S41.full

Supplementary material can be found at: http://n.neurology.org/content/suppl/2013/11/16/81.21_supplement_1.S 41.DC1

This article cites 15 articles, 2 of which you can access for free at: http://n.neurology.org/content/81/21_supplement_1/S41.full\#ref-list-1

This article has been cited by 2 HighWire-hosted articles: http://n.neurology.org/content/81/21_supplement_1/S41.full\#\#otherarti cles

This article, along with others on similar topics, appears in the following collection(s):

Clinical trials Methodology/study design

http://n.neurology.org/cgi/collection/clinical_trials_methodology_study design

Nerve tumor

http://n.neurology.org/cgi/collection/nerve_tumor

Neurofibromatosis

http://n.neurology.org/cgi/collection/neurofibromatosis

Information about reproducing this article in parts (figures,tables) or in its entirety can be found online at:

http://www.neurology.org/about/about_the_journal\#permissions

Information about ordering reprints can be found online:

http://n.neurology.org/subscribers/advertise

Neurology ${ }^{\circledR}$ is the official journal of the American Academy of Neurology. Published continuously since 1951, it is now a weekly with 48 issues per year. Copyright () 2013 American Academy of Neurology. All rights reserved. Print ISSN: 0028-3878. Online ISSN: 1526-632X.

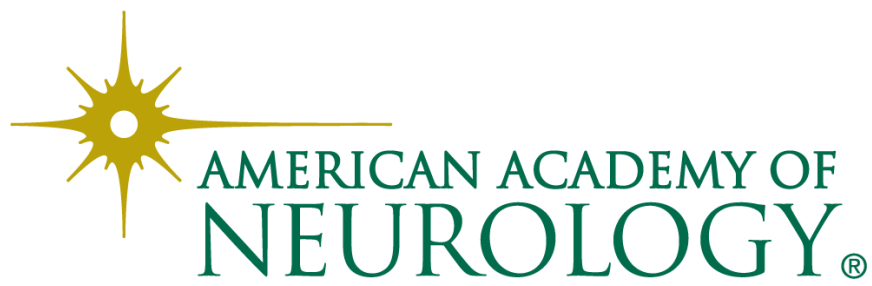

